\title{
Uluslararası Ticaretin Ekonomik Gelişme Üzerinde Etkileri: Gelişmiş ve Gelişmekte Olan Ülkeler için Bulgular ${ }^{1}$
}

\author{
Süreyya $\mathrm{KOVACI}^{1 *}$ \\ ${ }^{1}$ Asst. Prof. Dr., Burdur Mehmet Akif Ersoy University, Bucak Zeliha Tolunay School of Applied Technology \\ and Management, Department of Customs Business, Burdur, Turkey
}

Geliș Tarihi/Received: 20.09.2019

Kabul Tarihi/Accepted: 24.09.2019
Doi: doi.org/10.31200/makuubd.622417

Araştırma Makalesi/Research Article

\section{ÖZET}

Bu çalışmada, ülkelerin ekonomik gelişmişlikleri ve ticari açıklığı arasındaki ilişki ampirik olarak incelenmiştir. 2010-2016 döneminde 28 gelişmiş ve 30 gelişmekte olan ülke için panel veri analizi kullanılarak bulgular elde edilmiştir. Çalışmada, uluslararası ticaretin ülke gruplarında farklı etkilere sahip olduğu sonucuna ulaşılmıştır. Ticari açıklık, gelişmiş ülkelerde satın alma gücü paritesine dayalı kişi başına düşen gelir ile ölçülen ekonomik gelişmeyi pozitif etkilerken, gelişmekte olan ülkelerde ise negatif etkilemiştir. Gelişmiş ülkelerde, ekonomik gelişme üzerinde ticaretin dışında yatırım ve kamu harcaması istatistiksel olarak anlamlı etkilere sahip iken gelişmekte olan ülkelerde ise yatırım ve enflasyon istatistiksel olarak anlamlı etkilere sahiptir.

Anahtar kelimeler: Ekonomik Gelişme, Uluslararası Ticaret, Panel Veri Analizi.

\section{The Effects of International Trade on Economic Development: The Findings for Developed and Developing Countries}

\begin{abstract}
In this study, the relationship between trade openness and economic development of countries is examined empirically. The findings were obtained by using panel data analysis for 28 developed and 30 developing countries in the period from 2010 to 2016 . In this study, it is

\footnotetext{
${ }^{1} \mathrm{Bu}$ çalışma, 11.05.2018 tarihinde Antalya'da düzenlenmiş Uluslararası Sosyal Bilimler \& İnovasyon Kongresi'nde sunulan ve özet kitabında yer alan sözlü bildirinin geliştirilmiş halidir.

* Sorumlu yazar/Corresponding author

E-mail/e-ileti: skovaci@mehmetakif.edu.tr 


\section{Kovaci, $S$.}

concluded that international trade has different effects on country groups. While trade openness positively affects the economic development that is measured in per capita income based on purchasing power parity in developed countries, it affects negatively in developing countries. In developed countries, investment and government expenditure outside of trade have statistically significant effects on economic development, while in developing countries, investment and inflation have statistically significant effects.

Keywords: International Trade, Economic Development, Panel Data Analysis.

\section{GİRIŞ}

Uluslararası ticaret, ekonomi biliminde en eski ve en geniş alanlardan biridir. Ülkelerin ticari açıklığı, gelişmiş ve gelişmekte olan ülkelerde ekonomik büyümeyi artırarak gelir seviyelerini yükseltmektedir. Ancak, bu etkilerin gelişmekte olan ülkelerde ne ölçüde gerçekleştiğine dair bir tartışma uzun süredir devam etmektedir (Sakyi vd. 2015; Vamvakidis 2002). Dünya Bankası verilerine göre ticari açıklık 1980 yılında \%38.7 iken 2017 yılında \%57.8'e yükselmiştir. Son 30 yılda ithal ikamesine dayalı kalkınma stratejilerinin sınırlanması ve ticaretin serbestleşmesini destekleyen Uluslararası Para Fonu, Dünya Bankası gibi uluslararası finansal kurumların etkilerinin sonucu olarak ticarette serbestleşme özellikle geçiş ekonomilerinde ve gelişmekte olan ülkelerde gittikçe artmıştır (Zahonogo, 2016: 41-42).

Dünya ekonomisinde ülkelerin entegrasyonun artması, ülkeler arası gelir ve büyüme farklılıkları için önemli bir belirleyici olarak görülmektedir. Ticaret kaynak tahsis etkinliğini geliştirmekte, ülkelerin ölçek ve kapsam ekonomilerinden yararlanmalarını sağlamakta, bilginin yayılmasını kolaylaştırmaktadır. Aynı zamanda ticaret teknolojik gelişmeyi sağlayarak, iç ve dış piyasalarda rekabeti güçlendirerek ekonomik büyümeyi olumlu etkilemektedir. Ancak ülkelerin uygulamış oldukları ticaret politikasının gelir ve büyüme üzerinde etkileri tartışmalıdır. Bir taraftan ticaret engellerini düşürmek işlem maliyetlerini azaltarak uluslararası ticareti artırmakta ve ekonomik büyümeyi pozitif etkilemektedir. Dünyanın geri kalanına daha açık hale gelen gelişmekte olan ülkeler ve yükselen piyasa ekonomilerinin gelişmiş ekonomilerden teknoloji kullanma yeteneği elde edebilecekleri ileri sürülebilir. Diğer taraftan genç endüstrileri koruma ya da önemli sektörlerde stratejik ticaret politikası izlemek gibi korumacı politikalar ekonomik gelişme için faydalı görülmektedir (Busse ve Königer, 2012: 2). 
Ticaret ve büyüme arasında ilişkinin anlaşılmasına yönelik önemli yaklaşımlar sunulmaktadır. Büyüme Araştırma Geliştirme (AR-GE) faaliyetleri yoluyla sağlanıyorsa o zaman ticaret, ticaret ortaklarının teknolojik yeniliklerine ülkenin ulaşmasını sağlamaktadır. Ayrıca ticaret üreticilerin daha büyük pazarlara ulaşmasını sağlamaktadır ve artan getiriler yoluyla AR-GE'nin gelişimini teşvik etmektedir. Son olarak ticaret yeni ürünlere ve girdilere ulaşmayı sağlayarak büyüme üzerinde önemli bir rol oynamaktadır. Gelişmekte olan ülkelerin gelişmiş ülkelerle yaptıkları ticaretten fayda sağlayıp sağlamadıkları tartışılmaktadır (Yanikkaya, 2003: 61).

Ticari açıklık, teknolojinin yayılmasını kolaylaştırarak sırasıyla verimliliği, uluslararası rekabeti ve ihracat gelirlerini artırarak ekonomik büyümeyi pozitif etkilemektedir. Diğer teorik açıklamalar Singer-Prebisch tezi ile aynı doğrultuda ticari açıklığın özellikle düşük gelirli gelişmekte olan ülkelerde büyüme üzerinde negatif bir etkiye sahip olabileceği yönündedir (Vlastou, 2010; Tekin, 2012). Ticari açıklık daha verimli üretim yöntemleri ile teknolojik gelişmeler sağlayarak, kaynakların optimum tahsis edilmesiyle toplam faktör verimliliğini arttırmaktadır. Ülkeler arasında ticaretin serbestleşmesi, küreselleşmeyi ve güçlü, sürdürülebilir bir ekonomik büyümeyi sağlaması bakımından önemli bir role sahiptir (Bhattacharya ve Bhattacharya, 2016).

Bu çalışmada, 28 gelişmiş ve 30 gelişmekte olan ülkede 2010-2016 dönemi için ticaret ve gelir arasında ilişki ülke gruplarına göre ampirik olarak incelenmiştir. Çalışmanın sonraki bölümünde, ticari açıklığının etkilerini ampirik olarak inceleyen çalışmalara yer verilmiştir. Kullanılan ampirik modele, verilere ve tahmin sonuçlarına bölüm 3 'te değinilmiştir. En son kısımda, çalışmanın bulguları ve diğer çalışmalardan ayrılan yönleri yer almaktadır.

\section{LITERATÜR}

Ticari açıklık; serbest ticaret, ticaretin önünde engellerin azalması, küreselleşme ve ülkeler arasında mal ve hizmet ticaretinin gittikçe artması anlamına gelmektedir. Serbest ticaretin teknoloji transferi, yeteneklerin transferi, işgücü ve toplam faktör verimliliği ve ekonomik büyüme ve gelişme olmak üzere birçok pozitif ekonomik sonuç oluşturduğu ileri sürülmektedir. Literatürde yer alan pek çok çalışmada ticari açıklığın ekonomik büyümeyi pozitif etkilediği sonucu elde edilmiştir (Frankel ve Romer, 1999; Bahmani-Oskooee ve Niroomend 1999; Salinas ve Aksoy 2006; Yanikkaya 2003; Chang vd. 2009; Rassekh 2006; Busse ve Königer, 2012; Fetahi- Vehapi, 2015; Freund ve Bolaky 2008; Villaverde ve Maza 2011; Sakyi vd. 2012; Sakyi vd. 2015; Bhattacharya ve Bhattacharya, 2016). 


\section{Kovaci, $S$.}

Son dönemlerde yapılmış farklılaşan çalışmalara bakıldığında, Zahonogo (2016) ise Sahra Altı Afrika ülkelerinde, ticaretin ekonomik büyümeyi doğrusal olmayan biçimde etkilediğini bulmuştur. Vamvakidis (2002) ve Irwin ve Terviö (2002) belli bir dönemden sonra ticari açıklığının pozitif etkileri olduğu sonucuna ulaşmışlardır. Brunner (2003) uzun dönemde ticaretin gelir üzerinde büyük ve önemli bir etkisinin olduğunu fakat büyüme üzerinde etkilerin küçük olduğunu tespit etmiştir. Benzer şekilde Lee vd. (2004) ticari açıklığın büyüme üzerinde küçük ancak pozitif etkiye sahip olduğu sonucuna ulaşmışlardır. Aynı doğrultuda, Noguer ve Siscart (2005) ve Herzer (2013), ticaretin ülkelerin daha yüksek gelire ulaşmalarını sağladığını ileri sürmüşlerdir. Ticari açıklığın Rassekh (2006) düşük gelirli ülkelerde, Dufrenot (2010) büyüme oranlarının düşük olduğu ülkelerde daha fazla katkı yaptığı sonucuna ulaşmıştır. Kali vd. (2007) sadece ticaret hacminin değil aynı zamanda uluslararası ticaretin yapısının ekonomik büyüme ve gelişme için önemli olduğunu ileri sürmüşlerdir. Ticari açıklığın pozitif etkilerinin olup olmadığı uluslararası ticaretin yapısı ve ülkenin gelişmişlik düzeyi ile ilişskilidir.

Ticaretin ülkeler arasında yakınsama için gerekli olmadığını bir başka deyişle serbest ticarete şüpheyle yaklaşılması gerektiğini ileri süren Krugman ve Venables (1995) ile aynı doğrultuda bazı çalışmalar da öne çıkmaktadır. Özellikle az gelişmiş ülkeler için korumacı politikaları uygulaması gerektiği sonucunu üreten bu çalışmalardan, Were (2015) ticaretin etkisinin gelişmiş ve gelişmekte olan ülkeler grubunda pozitif, az gelişmiş ülkeler için etkinin anlamlı olmadığını ortaya koymuştur. Benzer şekilde, Ulaşan (2015) daha düşük ticaret engellerinin daha yüksek ekonomik büyüme ile ilişkili olmadığı sonucuna ulaşmış, BongaBonga ve Kinfack (2019) ise serbest ticaretten yüksek gelirli ülkelerin pozitif etkilendiğini ticaretin düşük gelirli ülkeleri ise etkilemediği sonucuna ulaşmışlardır. Vlastou (2010) ve Tekin (2012) ise, Afrika ülkelerinde ticari açıklık ve ekonomik gelişme arasında negatif ilişki bulmuşlardır. Dowrick ve Golley (2004) ticaretin etkilerinin zamanla ve ülkelerin gelişmişliklerine göre değiştiğini ileri sürmüşlerdir. Kim ve Lin (2009) ve Kim vd. (2011) ticari açıklıktan yüksek gelirli ülkelerin pozitif, düşük gelirli ülkelerin ise negatif etkilendiği sonucuna ulaşmışlardır. Ampirik çalışmalara ilişkin ayrıntılar Tablo 1'de sunulmuştur. 
Tablo 1. Literatürde öne çıkan çalışmalar

\begin{tabular}{|c|c|c|}
\hline Çalışma & Kapsam & Sonuç \\
\hline Busse ve Königer (2012) & $\begin{array}{l}108 \text { ülke ( } 87 \text { gelişmekte olan ülke), } \\
\text { 1971-2005, 5'er y1l ortalamalı } \\
\text { Dinamik Panel- Sistem Genelleştirilmiş } \\
\text { Moment Metodu (GMM) }\end{array}$ & $\begin{array}{l}\text { Ticaretin artması ilave } \\
\text { ulaşmayı teknolojilere } \\
\text { büyümeyi pozitif etkilemektedir. }\end{array}$ \\
\hline Frankel ve Romer (1999) & $\begin{array}{l}1985 \text { yllı } \\
150 \text { ülke } \\
\text { En Küçük Kareler (EKK) } \\
\text { Araç Değişken }\end{array}$ & $\begin{array}{l}\text { Ticaret, fiziki ve beşeri sermayenin } \\
\text { birikimini sağlayarak ve verilen sermaye } \\
\text { düzeyleri için artan çıktılar yoluyla geliri } \\
\text { artırmaktadır. }\end{array}$ \\
\hline Salinas ve Aksoy (2006) & $\begin{array}{l}\text { 1970-2004 dönemi } \\
\text { Gelişmekte olan } 39 \text { ülke } \\
\text { Panel veri Sabit etki }\end{array}$ & $\begin{array}{l}\text { Ticari açıklığın büyüme üzerinde pozitif } \\
\text { etkisi bulunmuştur. }\end{array}$ \\
\hline Zahonogo (2016) & $\begin{array}{l}\text { 1980-2012 dönemi } \\
42 \text { Sahra Altı Afrika ülkesi } \\
\text { Dinamik Panel }\end{array}$ & $\begin{array}{l}\text { Etki belirli bir eşik noktasına kadar } \\
\text { pozitif, daha sonra ilişkinin yönü } \\
\text { değişmiş̧tir. }\end{array}$ \\
\hline Yanikkaya (2003) & $\begin{array}{l}\text { EKK, } \\
\text { Görünürde İlişkisiz Regresyon (GİR), } \\
\text { Üç Aşamalı EKK (ÜAEKK) }\end{array}$ & $\begin{array}{l}\text { Ticari açıklık ve ekonomik büyüme } \\
\text { arasında pozitif ilişki bulunmuştur. } \\
\text { Ticaret engellerinin büyüme üzerinde } \\
\text { etkileri ülkelerin gelişmişliklerine göre } \\
\text { değişmektedir. Gelişmekte olan } \\
\text { ülkelerde de ilişki pozitiftir. }\end{array}$ \\
\hline Fetahi- Vehapi (2015) & $\begin{array}{l}\text { EKK, Sabit Etki, GMM } \\
\text { 1996-2012 dönemi } \\
\text { Güney Doğu Avrupa Ülkeleri } 10 \text { ülke }\end{array}$ & $\begin{array}{l}\text { Ticari açıklığın büyüme üzerinde pozitif } \\
\text { etkisi vardır. }\end{array}$ \\
\hline Tekin (2012) & $\begin{array}{l}\text { Panel Granger Nedensellik } \\
\text { 1970-2010 dönemi } \\
\text { Az gelişmiş } 27 \text { Afrika ülkesi }\end{array}$ & $\begin{array}{l}\text { Ticari açıklığın büyüme üzerinde etkisi } \\
\text { yoktur. Bazı ülkelerde negatif etki } \\
\text { bulunmuştur. }\end{array}$ \\
\hline $\begin{array}{l}\text { Bahmani-Oskooee ve } \\
\text { Niroomend (1999) }\end{array}$ & $\begin{array}{l}\text { 1960-1992 dönemi } \\
59 \text { ülke } \\
\text { Eşbütünleşme }\end{array}$ & $\begin{array}{l}\text { Uzun dönemde pozitif } \text { ilişki } \\
\text { bulunmuştur. }\end{array}$ \\
\hline Freund ve Bolaky (2008) & $\begin{array}{l}2000-2005 \text { dönemi } \\
126 \text { ülke } \\
\text { EKK }\end{array}$ & $\begin{array}{l}\text { Ticari açıklığın kişi başına geliri } \\
\text { arttırdığı sonucuna ulaşılmıştır. }\end{array}$ \\
\hline Vlastou (2010) & $\begin{array}{l}\text { 1960-2003 dönemi } \\
34 \text { Afrika ülkesi } \\
\text { Dinamik panel, } \\
\text { Eşbütünleşme } \\
\text { Nedensellik }\end{array}$ & $\begin{array}{l}\text { Ticari açıklık ekonomik büyümeyi } \\
\text { negatif etkilemekte ve nedensellik tek } \\
\text { yönlü ticari açıklıktan ekonomik } \\
\text { büyümeye doğrudur. }\end{array}$ \\
\hline Ulaşan (2015) & $\begin{array}{l}119 \text { ülke } \\
\text { Dinamik panel veri }\end{array}$ & $\begin{array}{l}\text { Daha düşük ticaret engellerinin daha } \\
\text { yüksek ekonomik büyüme ile ilişkili } \\
\text { olmadığı sonucuna ulaşılmışır. }\end{array}$ \\
\hline Sakyi vd. (2012) & $\begin{array}{l}1970-2009 \text { dönemi } \\
85 \text { orta gelirli ekonomi } \\
\text { Panel eş bütünleşme } \\
\text { Nedensellik. }\end{array}$ & $\begin{array}{l}\text { Uzun dönemde ticari açılık ve } \\
\text { ekonomik geliş̧me arasında önemli bir } \\
\text { ilişki bulunmuştur. }\end{array}$ \\
\hline Sakyi vd. (2015) & $\begin{array}{l}\text { 1970-2009 dönemi } \\
115 \text { gelişmekte olan ülke } \\
\text { Panel eş bütünleşme } \\
\text { Nedensellik. }\end{array}$ & $\begin{array}{l}\text { Gelişmekte olan ülkelerde uzun } \\
\text { dönemde pozitif yönlü bir ilişki, ticari } \\
\text { açıklığın gelir seviyesinin hem sebebi } \\
\text { hem de sonucu olduğu, kısa dönem için } \\
\text { yine iki yönlü ilişki bulunmuştur. }\end{array}$ \\
\hline
\end{tabular}




\section{Kovaci, $S$.}

\begin{tabular}{|c|c|c|}
\hline $\begin{array}{l}\text { Bhattacharya ve Bhattacharya } \\
\text { (2016) }\end{array}$ & $\begin{array}{l}\text { BRICS ülkeleri } \\
\text { Panel eş bütünleşme } \\
\text { Nedensellik }\end{array}$ & $\begin{array}{l}\text { Ticari açıklık ekonomik büyümeyi } \\
\text { pozitif olarak etkilemektedir. }\end{array}$ \\
\hline Vamvakidis (2002) & $\begin{array}{l}\text { 1870-1970 dönemi } \\
\text { 1970-1990 dönemi }\end{array}$ & $\begin{array}{l}\text { Serbest ticaret ve büyüme arasında } \\
\text { pozitif ilişkiyi sadece } 1970 \text { sonras1 } \\
\text { dönem için doğrulamıştır. }\end{array}$ \\
\hline Irwin ve Terviö (2002) & $\begin{array}{l}\text { 1913, 1928, 1938, 1954, 1964, 1975, 1985, } \\
\text { 1990 y1lları } \\
\text { 36, 41, 41, 41, 63, 52, 62-40, } 52 \text { ülke } \\
\text { EKK } \\
\text { İki Aşamalı EKK (İAEKK) }\end{array}$ & $\begin{array}{l}\text { I. Dünya savaş1 sonrası dönem için } \\
\text { ticaretin geliri } \\
\text { ulaşmışlardıracağ }\end{array}$ \\
\hline Brunner (2003) & $\begin{array}{l}\text { 1960-1992 dönemi } \\
125 \text { ülke } \\
\text { Dinamik Panel }\end{array}$ & $\begin{array}{l}\text { Uzun dönemde ticaretin gelir üzerinde } \\
\text { büyük ve önemli bir etkisi var iken } \\
\text { büyüme üzerindeki etkisinin küçük } \\
\text { olduğu belirtilmiştir. }\end{array}$ \\
\hline Lee vd. (2004) & $\begin{array}{l}1960-2000 \text { dönemi } \\
5 \text { y1llık } 8 \text { dönem } \\
100 \text { ülke } \\
\text { Sabit etkiler, Fark GMM }\end{array}$ & $\begin{array}{l}\text { Ticari açılık büyüme üzerinde küçük } \\
\text { ancak pozitif etkiye sahiptir. }\end{array}$ \\
\hline Noguer ve Siscart (2005) & $\begin{array}{l}1985 \text { dönemi } \\
97 \text { ülke } \\
\text { EKK, İAEKK }\end{array}$ & $\begin{array}{l}\text { Ticaretin ülkelerin daha yüksek gelire } \\
\text { ulaşmasını sağladığı bulunmuştur. }\end{array}$ \\
\hline Were (2015) & $\begin{array}{l}\text { 1991-2011 dönemi } \\
85 \text { ülke (gelişmiş, gelişmekte olan ve az } \\
\text { gelişmişülkeler) } \\
\text { EKK, Araç değişken. }\end{array}$ & $\begin{array}{l}\text { Ticaretin etkisi gelişmiş ve gelişmekte } \\
\text { olan ülkeler grubunda pozitif iken, az } \\
\text { gelişmiş ülkeler için etki anlaml } \\
\text { değildir. }\end{array}$ \\
\hline Herzer (2013) & $\begin{array}{l}\text { 1960-2008 dönemi } \\
91 \text { gelişmiş ve gelişmekte olan ülke } \\
\text { Panel eş bütünleşme Dinamik EKK }\end{array}$ & $\begin{array}{l}\text { Ticaretin gelire etkileri anlamlı ve } \\
\text { pozitif yöndedir. }\end{array}$ \\
\hline Dowrick ve Golley (2004) & $\begin{array}{l}\text { 1960-1980 dönemi } \\
\text { 1980-2000 dönemi }\end{array}$ & $\begin{array}{l}\text { 1960-1980 arası yakınsamayı sağladığ } 1 \text {, } \\
1980-2000 \text { arası ticaretin etkilerinin } \\
\text { zengin ülkeler için daha fazla olduğu az } \\
\text { gelişmiş ülkeler için ise etkilerin az } \\
\text { olduğu bulunmuştur. Ticaretin etkileri } \\
\text { zamanla ve ülkelerin gelişmişliklerine } \\
\text { göre değişmektedir. }\end{array}$ \\
\hline Kim ve Lin (2009) & $\begin{array}{l}\text { 1960-2000 dönemi } \\
61 \text { ülke (yüksek ve düşük gelirli ülke) } \\
\text { Panel GMM }\end{array}$ & $\begin{array}{l}\text { Ticaret yüksek gelirli ülkelerde pozitif } \\
\text { etkili iken düşük gelirli ülkelerde bu etki } \\
\text { görülmemektedir. }\end{array}$ \\
\hline Rassekh (2007) & $\begin{array}{l}\text { 1960-1985 dönemi } \\
150 \text { ülke } \\
\text { EKK } \\
\text { Araç Değişken }\end{array}$ & $\begin{array}{l}\text { Ticaretin daha düşük gelirli ülkeler için } \\
\text { daha olumlu katkı yaptığı sonucuna } \\
\text { ulaşmıştır. }\end{array}$ \\
\hline Kim vd. (2011) & $\begin{array}{l}\text { 1960-2000 dönemi } \\
61 \text { ülke (yüksek ve düşük gelirli ülke) } \\
\text { Panel GMM }\end{array}$ & $\begin{array}{l}\text { Daha büyük ticari açıklık yüksek gelirli } \\
\text { ülkelerin kalkınmasında pozitif etkilere } \\
\text { sahip iken düşük gelirli ülkelerde etki } \\
\text { negatiftir. }\end{array}$ \\
\hline Dufrenot vd. (2010) & $\begin{array}{l}\text { 1980-2006 dönemi } \\
75 \text { gelişmekte olan ülke } \\
\text { Kantil Regresyon. }\end{array}$ & $\begin{array}{l}\text { Ticari açıklı̆ğın etkisi büyüme oranları } \\
\text { düşük olan ülkelerde, yüksek olanlara } \\
\text { göre daha yüksektir. }\end{array}$ \\
\hline $\begin{array}{l}\text { Bonga-Bonga ve Kinfack } \\
(2019)\end{array}$ & $\begin{array}{l}\text { 1970-2016 dönemi } \\
38 \text { Afrika ülkesi } \\
\text { Araç Değişken Panel Yumuşak Geçiş } \\
\text { Regresyon }\end{array}$ & $\begin{array}{l}\text { Orta ve yüksek gelirli ülkelerde ilişki } \\
\text { pozitif iken düşük gelirli ülkelerde ilişki } \\
\text { yoktur. }\end{array}$ \\
\hline
\end{tabular}




\begin{tabular}{|l|l|l|}
\hline Chang vd. (2009) & $\begin{array}{l}1960-2000 \text { dönemi } \\
\text { 22 gelişmişülke } \\
60 \text { gelişmekte olan ülke } \\
\text { Panel veri GMM }\end{array}$ & $\begin{array}{l}\text { Ticari açıklığın ekonomik büyüme ile } \\
\text { pozitif ilişkili olduğu sonucuna } \\
\text { ulaşmışlardır. }\end{array}$ \\
\hline Villaverde ve Maza (2011) & $\begin{array}{l}1970-2005 \text { dönemi } \\
101 \text { ülkede } \\
\text { Panel veri } \\
\text { EKK } \\
\text { GMM }\end{array}$ & $\begin{array}{l}\text { Ekonomik küreselleşmenin ekonomik } \\
\text { büyümeye pozitif yansiyacağ1 ve } \\
\text { ülkelerin birbirine yakınsayacağ1 } \\
\text { sonucuna ulaşmışlardır. }\end{array}$ \\
\hline
\end{tabular}

\section{YÖNTEM}

\subsection{Ekonometrik Model ve Veri Seti}

Ampirik kısımda, dar bir çerçeve olmasına rağmen ekonomik gelişme göstergesi olarak kullanılabilen satın alma gücü paritesine (SAGP) dayalı kişi başına Gayri Safi Yurtiçi Hâsıla’yı (KBGSYH) açıklamaya odaklanılmaktadır. Uluslararası ticaretin ekonomik gelişmeye etkilerini incelemek için, temel büyüme modelleri kapsamında, aşağıdaki denklem tahmin edilmiştir.

$$
\operatorname{lnKBGSYH} \mathrm{H}_{\mathrm{it}}=\beta_{0}+\beta_{1} \ln \mathrm{T}_{\mathrm{it}}+\beta_{2} \ln \mathrm{Y}_{\mathrm{it}}+\beta_{3} \ln \mathrm{KH}_{\mathrm{it}}+\beta_{4} \operatorname{lnENF_{\mathrm {it}}}+\beta_{5} \Delta \ln \mathrm{N}_{\mathrm{t}}+\epsilon_{\mathrm{it}}
$$

Denklem 1'de $€_{\mathrm{it}}=\mathrm{u}_{\mathrm{i}}+\mu_{\mathrm{it}}$, ui ve $\mu_{\mathrm{it}}$ strasıyla zamana göre değişmez ülkelere ilişkin gözlenemeyen etkileri ve modelin hata terimini ifade etmektedir. Denklemde i ülkeleri, $\mathrm{t}$ ise yıl olarak dönemi göstermektedir. Çalışma, 2010-2016 döneminde 28 gelişmiş ülke (GÜ) ve 30 gelişmekte olan ülkeyi (GOÜ) kapsamaktadır. Çalışmaya dâhil edilen ülkeler, Birleşmiş Milletler'in 2014 yılı Dünya Ekonomik Durum ve Beklentileri raporuna göre sınıflandırılmıştır (United Nations, 2014). Kullanılan veriler, Dünya Bankası'nın veri tabanından elde edilmiş ve logaritmaları alınarak modelde değerlendirilmiştir. Modelde kullanılan değişkenlere ait bilgiler ve açıklayıcı değişkenlerin etkileri Tablo 2'de sunulmaktadır.

Tablo 2. Araştırmada kullanılan değişkenler

\begin{tabular}{|c|c|c|}
\hline \multicolumn{3}{|c|}{ Panel A: Bağımlı değișken } \\
\hline Değişken (Sembol) & \multicolumn{2}{|l|}{ Tanım } \\
\hline $\begin{array}{l}\text { Ekonomik Gelişme } \\
\text { (KBGSYH) }\end{array}$ & \multicolumn{2}{|c|}{ SAGP dayalı olarak KBGSYH (GSYH-2011 sabit fiyatlarıyla ABD Doları) } \\
\hline \multicolumn{3}{|c|}{ Panel B: Açıklayıcı değişkenler } \\
\hline Değişken (Sembol) & Tanım & Beklenen Etki \\
\hline Ticari Açıklık (T) & İhracat ve ithalat toplamının GSYH içinde payı & Belirsiz \\
\hline Yatırım (Y) & Gayri Safi Sabit Sermaye Oluşumunun GSYH içinde payı & Pozitif \\
\hline Enflasyon (ENF) & Tüketici fiyat endeksi (yıllık) & Belirsiz \\
\hline Nüfus (N) & Toplam nüfusta artış & Belirsiz \\
\hline Kamu Harcamaları (KH) & Kamunun nihai tüketim harcamalarının GSYH içinde payı & Belirsiz \\
\hline
\end{tabular}


Ticari açıklık çeşitli şekillerde ölçülmesine rağmen en geçerli ve geleneksel ölçümlerin Mi/GSYHi, Xi/GSYHi, (X+M)i/GSYHi, ortak özellikleri GSYH payları şeklinde ifade edilmiş olmalarıdır (Tablo 3). Yaygın olarak kullanılan geleneksel ticari açıklık ölçüsü, (X+M)i/GSYHi, ihracat ve ithalat toplamının GSYH'e oranıdır (Winters, 2004: 8; Bejan, 2006: 4; Huchet vd., 2011: 4). Aykırı değerleri düzeltmek için alternatif ölçümler Frankel (2000), Li vd. (2004), Alcala' ve Ciccone (2004) tarafindan geliştirilmiştir. Belirtilen ölçümlerin çoğu sezgisel olarak anlaşılmaktadır ancak taşıdıkları belirsizlik bakımından başarısız oldukları düşünülmektedir (Squalli ve Wilson, 2011). Bu çalışmada, ticari açıklık ölçüsü olarak ihracat ve ithalat toplamının GSYH payı kullanılmıştır. Ticari açıklığın ekonomik gelişme üzerinde etkilerinin ülkeden ülkeye değişmesi beklenmektedir. Çünkü Kali vd. (2007) çalışmasında da vurgulandı̆̆ı gibi ticareti yapılan malların katma değer bakımından sağladığı kazanç farklılaşacaktır.

Tablo 3. Ticari açıklık ölçüsü

\begin{tabular}{ll}
\hline Ölçü & Tanım \\
\hline Mi/GSYHi & İthalat payı, ihracatın GSYH'e oranı \\
Xi/GSYHi & İhracat payı, ithalatın GSYH'e oranı \\
$(\mathrm{X}+\mathrm{M}) \mathrm{i} / \mathrm{GSYHi}$ & Ticaret payı, ihracat ve ithalatın GSYH’e oranı \\
$1-$ - $(\mathrm{X}+\mathrm{M}) \mathrm{i} / 2 \mathrm{GSYHi}]$ x 100 & Düzeltilmiş ticaret payı, Frankel (2000) tarafından önerilmiş alternatif bir yöntem. \\
$\mathrm{M} / \mathrm{GSYHi}-\left(1-\mathrm{GSYHi} / \sum_{i=1}^{k} \mathrm{GSYHi}\right)$ & Düzeltilmiş ticaret payı, Frankel (2000) önerdiği yöntem Li vd. (2004) tarafından \\
& değiştirilmiş. \\
$(\mathrm{X}+\mathrm{M}) \mathrm{i} / \mathrm{rGSYHi}$ & Alcala' ve Ciccone (2004) takiben reel ticaret payı, satın alma gücü paritesine dayalı \\
& olarak düzenlenmiş GSYH \\
\hline
\end{tabular}

Kaynak: Squalli ve Wilson (2011: 1746)

Yatırım olarak, gayri safi sabit sermaye oluşumunun GSYH içinde payı kullanılmıştır. Bütün ekonomi yaklaşımlarında, yatırım dolayısıyla sermaye birikimi ekonomik gelişmenin motoru olarak düşünülmekte çünkü sermaye kullanımı sermaye yoğun malların üretimini arttırmakta bu malların tüketimi gelirin artışı ile arttığı için sermaye birikimi gelir artışını teşvik etmektedir. $\mathrm{Bu}$ nedenle yatırımların ekonomik gelişmeyi pozitif etkilemesi beklenmektedir (Anwer ve Sampet, 1999). Enflasyon göstergesi olarak Tüketici fiyat endeksi kullanılmıştır. Enflasyonun artmasıyla paranın satın alma gücü azalacağı için tüketim azalacak ve bu nedenle kişi başına gelir azalacaktır. Yüksek enflasyon ekonomide belirsizliği arttırdığı için yatırımları olumsuz etkilemektedir (Fischer, 1993; Barro, 2005). Diğer taraftan kisa dönemde enflasyon ve işsizlik arasında negatif bir ilişki olduğunu gösteren Phillips Eğrisi olarak bilinen bir başka deyişle ekonomide toplam talep artışıyla GSYH artışı sağlanabilir ve bu sebeple işsizlik 
azaltılabilir ancak aynı zamanda talep artışı enflasyonu artıracaktır. Dolayısıyla enflasyonun etkisi de ülke gruplarına göre değişebilecektir. Nüfus artışı kişi başına gelir büyümesinde önemli bir azalmaya neden olacaktır nüfus ve işgücü artmadığında işgücü başına sermaye ve dolayısıyla işgücü başına çıktı zamanla artacaktır (Easterlin, 1967). Oysa nüfusun yoğun olmadığ1 ülkelerde işgücü talebini karşılamak için nüfus artış1 işgücü faktörünü olumlu etkileyeceği için GSYH artışı sağlayabilir bu nedenle pozitif bir etki de görülebilir. Kamu harcaması olarak kamunun nihai tüketim harcamalarının GSYH içinde payı kullanılmıştır. Kamu harcamaları ekonomik aktiviteyi yavaşlatmaktadır (Abrams, 1999), diğer taraftan Keynesyen düşünce çerçevesinde kamu harcamalarında artış ekonomiyi genişletebilmektedir (Loizides ve Vamvoukas, 2005). Gelişmiş ülkelerde dışlama etkisi sebebiyle ekonomik gelişmeyi olumsuz etkilerken gelişmekte olan ülkelerde ise özel sektör yatırımlarının yetersiz olduğu durumlarda ekonomik gelişmeyi sağlamak için kamu harcamalarını arttırmak politika aracı olarak kullanılabilir dolayısıyla kamu harcamalarının etkileri pozitif olabilir. Bu sebeple kamu harcamalarının da işareti belirsizdir, bir başka deyişle ülkenin gelişmişliğine göre değişecektir.

\subsection{Bulgular}

Gelişmiş ülkelerde değişkenlere ait korelâsyon sonuçları Tablo 4'te yer almaktadır. Bağımsız değişkenler arasında ilişkiyi gösteren korelâsyon katsayılarına bakıldığında, istatistiksel olarak anlamlı en güçlü ilişki -0.4075 değeri ile nüfus ve ticari açıklık arasındadır.

Tablo 4. Gelişmiş ülkelerde değişkenlerin korelâsyon katsayıları

\begin{tabular}{|c|c|c|c|c|c|c|}
\hline & KBGSYH & $\mathrm{T}$ & $\mathrm{Y}$ & ENF & $\mathrm{N}$ & $\mathrm{KH}$ \\
\hline KBGSYH & 1 & & & & & \\
\hline $\mathrm{T}$ & $0.4703 * * *$ & 1 & & & & \\
\hline Y & 0.0622 & -0.087 & 1 & & & \\
\hline ENF & -0.0327 & -0.0321 & -0.105 & 1 & & \\
\hline $\mathrm{N}$ & 0.0541 & $-0.4075^{*} * *$ & -0.1164 & -0.0369 & 1 & \\
\hline KH & $-0.1625^{* *}$ & $-0.1393 *$ & -0.0827 & $0.2212 * * *$ & $-0.2663 * * *$ & 1 \\
\hline
\end{tabular}

Gelişmekte olan ülkelerde değişkenlere ait korelâsyon sonuçları Tablo 5'te yer almaktadır. Bağımsız değişkenler arasında, istatistiksel olarak anlamlı en güçlü ilişki -0.4665 değeri ile nüfus ve ticari açıklık arasındadır. Düşük korelâsyon katsayıları gelişmiş ve gelişmekte olan ülkelere ilişkin kurulan modellerde çoklu doğrusal bağlantı açısından sorun olmadığını göstermektedir. 


\section{Kovaci, $S$.}

Tablo 5. Gelişmekte olan ülkelerde değişkenlerin korelâsyon katsayıları

\begin{tabular}{|c|c|c|c|c|c|c|}
\hline & KBGSYH & $\mathrm{T}$ & $\mathrm{Y}$ & ENF & $\mathrm{N}$ & $\mathrm{KH}$ \\
\hline KBGSYH & 1 & & & & & \\
\hline $\mathrm{T}$ & -0.0052 & 1 & & & & \\
\hline $\mathrm{Y}$ & $0.1968 * * *$ & $0.367 * * *$ & 1 & & & \\
\hline ENF & $0.1464 * *$ & $-0.2914 * * *$ & $-0.147 * *$ & 1 & & \\
\hline $\mathrm{N}$ & -0.0653 & $-0.4665 * * *$ & -0.0977 & 0.0121 & 1 & \\
\hline KH & 0.0929 & 0.1025 & 0.1008 & $-0.1631 * *$ & $-0.2107 * * *$ & 1 \\
\hline
\end{tabular}

Gelişmiş ve gelişmekte olan ülkeler için tahmin edilen modelin sonuçları Tablo 6'da yer almaktadır. En uygun tahminciye karar vermek amacıyla sırasıyla en küçük kareler tahmincisinin uygun olup olmadığını belirlemek için F-testi ve tesadüfî etkiler tahmincisinin uygun olup olmadığını belirlemek için ise Hausman (1978) testi yapılmıştır. Bu testlerde hipotezler reddedildiği için sabit etkiler tahmincisinin kullanılması uygun bulunmuştur. Modelde otokorelasyon sorununun varlığını test etmek için Woolridge (2002) testi yapılmış birinci dereceden otokorelasyonun olmadığ hipotezi reddedilmiştir. Greene (2000) tarafından önerilen düzeltilmiş Wald testi sonucu hata terimlerinin varyansının değişmediği hipotezi reddedilmiştir. Yatay kesit bağımlılığı için Pesaran (2004)'ın CD-testi kullanılmış ve yatay kesit bağımlılığı yoktur hipotezi sınanmıştır (Tatoğlu, 2012). Testler sonucu, zaman etkilerinin olmadığı modellerde otokorelasyon, değişen varyans ve yatay kesit bağımlılığı sorunları olduğu görülmüştür. $\mathrm{Bu}$ nedenle Driscoll- Kraay (1998) dirençli standart hatalar tahmincisi kullanılmıştır. Zaman etkilerinin dâhil edildiği modellerde otokorelasyon ve değişen varyans sorunları tespit edilmiş ve bu nedenle Arellano (1987), Froot (1989) ve Rogers (1993) dirençli standart hatalar tahmincisi kullanılmıştır. 
Tablo 6. Uluslararası ticaretin ekonomik gelişmeye etkilerinin tahmini

\begin{tabular}{|c|c|c|c|c|}
\hline \multicolumn{5}{|c|}{ Bağımlı Değişken: Kişi Başına GSYH } \\
\hline & $\begin{array}{l}\text { G̈̈ } \\
(\mathbf{1})\end{array}$ & $\begin{array}{l}\text { GOÜ } \\
(2)\end{array}$ & $\begin{array}{l}\text { G̈̈ } \\
\text { (3) }\end{array}$ & $\begin{array}{l}\text { GOÜ } \\
(4)\end{array}$ \\
\hline Ticari Açıklık & $\begin{array}{l}0.145 * * * \\
(0.0151)\end{array}$ & $\begin{array}{l}-0.264 * * * \\
(0.0379)\end{array}$ & $\begin{array}{l}0.159 * * * \\
(0.0567)\end{array}$ & $\begin{array}{l}-0.0974 * * \\
(0.0461)\end{array}$ \\
\hline Yatırım & $\begin{array}{l}0.233 * * * \\
(0.0542)\end{array}$ & $\begin{array}{l}0.163 * * * \\
(0.0252)\end{array}$ & $\begin{array}{l}0.208 * * * \\
(0.0502)\end{array}$ & $\begin{array}{l}0.153 * * \\
(0.0560)\end{array}$ \\
\hline Enflasyon & $\begin{array}{l}-0.844 * * * \\
(0.202)\end{array}$ & $\begin{array}{l}-0.297 * * * \\
(0.0722)\end{array}$ & $\begin{array}{l}-0.367 \\
(0.346)\end{array}$ & $\begin{array}{l}-0.271 * * * \\
(0.0729)\end{array}$ \\
\hline Nüfus artışı & $\begin{array}{l}0.526 \\
(0.385)\end{array}$ & $\begin{array}{l}-0.267 \\
(2.499)\end{array}$ & $\begin{array}{l}0.313 \\
(0.540)\end{array}$ & $\begin{array}{l}7.885 \\
(5.286)\end{array}$ \\
\hline Kamu harcaması & $\begin{array}{l}-0.388 * * * \\
(0.0951)\end{array}$ & $\begin{array}{l}0.153 * * * \\
(0.0247)\end{array}$ & $\begin{array}{l}-0.353 * * \\
(0.159)\end{array}$ & $\begin{array}{l}0.0172 \\
(0.0480)\end{array}$ \\
\hline Sabit terim & $\begin{array}{l}14.26 * * * \\
(1.001)\end{array}$ & $\begin{array}{l}10.86 * * * \\
(0.338)\end{array}$ & $\begin{array}{l}11.96 * * * \\
(1.324)\end{array}$ & $\begin{array}{l}10.28 * * * \\
(0.362)\end{array}$ \\
\hline Zaman Etkileri & Yok & Yok & Var & Var \\
\hline F testi & $471.76 * * *$ & $914.38 * * *$ & $643.05 * * *$ & $1516.30 * * *$ \\
\hline CD test & $13.047 * * *$ & $7.114 * * *$ & -0.416 & -1.320 \\
\hline Hausman test & $42.67 * * *$ & $16.99 * * *$ & $42.77 * * *$ & $16.54 * * *$ \\
\hline Wooldridge & $63.610 * * *$ & $26.353 * * *$ & $70.176 * * *$ & $27.423 * * *$ \\
\hline Wald testi & $1.3 \mathrm{e}+05^{* * *}$ & $4126.96 * * *$ & $6014.23^{* * *}$ & $11630.00 * * *$ \\
\hline F ist. & $2124.0 * * *$ & $403.9 * * *$ & $139.0 * * *$ & $33.40 * * *$ \\
\hline $\mathrm{R}^{2}$ & 0.6573 & 0.5337 & 0.763 & 0.729 \\
\hline $\mathrm{N}$ & 168 & 173 & 168 & 173 \\
\hline
\end{tabular}

Gelişmiş ülkelere ilişkin modelde nüfus artışı dışında bütün açıklayıcı değişkenler istatistiksel olarak beklenen yönde anlamlıdır. Ticari açıklık \%1 arttığında kişi başına gelir ile ölçülen ekonomik gelişme \%0.145 artmaktadır. Gelişmekte olan ülkelere ilişkin modelde nüfus artışı dışında bütün açıklayıcı değişkenler istatistiksel olarak beklenen yönde anlamlıdır. Ticari açıklık \%1 arttığında kişi başına gelir ile ölçülen ekonomik gelişmeyi \%0,264 azaltmaktadır. Bu sonucun Afrika ülkeleri için yapılmış Vlastou (2010) ve Tekin (2012) ve ticaretin etkilerinin zamanla ve ülkelerin gelişmişliklerine göre değiştiğini ileri süren Dowrick ve Golley (2004), Kim ve Lin (2009) ve Kim vd. (2011) ile benzer nitelikte sonuçlardır. Aynı zamanda bu sonuçların gelişmekte olan ülkeler için yapılan Yanikkaya (2003), Busse ve Königer (2012) ve Sakyi vd. (2015) çalışmalarından farklılaştığı söylenebilir. Zaman etkilerinin dâhil edildiği ve gelişmiş ülkeler için sonuçların elde edildiği, 3 nolu modelde, enflasyon ve nüfus artışı anlamlı değil iken ticari açıklık, yatırım ve kamu harcaması ekonomik gelişmeyi istatistiksel olarak anlamlı etkilemektedir. Ticari açıklık \%1 arttığında ekonomik gelişme \%0.159 artmaktadır. 4 nolu modelde nüfus artışı ve kamu harcaması istatistiksel olarak anlamlı değil iken enflasyon, yatırım ve ticari açıklık istatistiksel olarak anlamlı etkilere sahiptir. Ticari açıklık \%1 arttığında ekonomik gelişmeyi \%0.097 azaltmaktadır. Zaman etkilerinin yer alması da nitelik olarak sonucu değiştirmemiş ve gelişmekte olan ülkelerin serbest ticaretten olumsuz etkilendiği sonucuna ulaşılmıştır. 


\section{Kovacı, $S$.}

\section{SONUÇ}

2010-2016 yılları arasında, 28 gelişmiş ve 30 gelişmekte olan ülkede ticari açıklığın ekonomik gelişme üzerinde etkileri incelenmiştir. Panel veri tahmin yöntemleri kullanılarak elde edilen sonuçlara göre ticari açıklık, SAGP’ye dayalı KBGSYH ile ölçülen ekonomik gelişmeyi gelişmiş ülkelerde pozitif, gelişmekte olan ülkelerde ise negatif etkilemektedir. Gelişmiş ülkelerde ticaretin dışında ekonomik gelişme üzerinde anlamlı etkilere sahip değişkenler yatırım ve kamu harcaması iken gelişmekte olan ülkelerde yatırım ve enflasyondur. Gelişmiş ülkelerde kamu harcamalarının, gelişmekte olan ülkelerde enflasyonun olumsuz etkileri istatistiksel olarak anlamlıdır. Diğer taraftan yatırımların etkisi hem gelişmiş hem de gelişmekte olan ülkelerde pozitif bulunmuştur.

$\mathrm{Bu}$ sonuçlar kapsamında, ticaret savaşlarının başladığı, bir başka deyişle korumacı politikaların öne çıktığı son yıllarda gelişmiş ülkelerden çok gelişmekte olan ülkelerin korumacı politikalara ihtiyaç duyduğunu, serbest ticaretin gelişmiş ülkeler için fayda sağladığını söylemek yanlış olmayacaktır. Ayrıca, ekonomi yönetimlerinin daha etkin dış ticaret politikaları belirleyebilmeleri açısından gelişmekte olan ülkelerde ticari açıklığın sektörel olarak etkilerini inceleyen çalışmalara ihtiyaç olduğu söylenebilir.

\section{Ek 1. Analize Dahil Edilen Ülkeler}

Gelişmiş Ülkeler: Avustralya, Avusturya, Belçika, Kanada, Hırvatistan, Çekya, Danimarka Finlandiya, Fransa, Almanya, Macaristan, İzlanda, İrlanda, İtalya, Japonya, Lüksemburg, Hollanda, Yeni Zelanda, Norveç, Polonya, Portekiz, Slovakya, Slovenya, İspanya, İsveç, İsviçre, İngiltere, Amerika Birleşik Devletleri.

Gelişmekte Olan Ülkeler: Cezayir, Arjantin, Bolivya, Brezilya, Kamerun, Şili, Kolombiya Kongo Cumhuriyeti, Kosta Rika, Misır, El Salvador, Honduras, Endonezya, İran, Jamaika, Malezya, Meksika, Fas, Nijerya, Pakistan, Panama, Paraguay, Peru, Güney Afrika, Sri Lanka, Tayland, Tunus, Türkiye, Uruguay, Venezuela.söylenebilir. 


\section{Gelişmiş Ülkelerin Açıklayıcı İstatistikleri}

\begin{tabular}{|l|l|l|l|l|l|}
\hline Değişken & Ortalama & Std. Sapma & Minimum & Maksimum & Gözlem Sayısı \\
\hline Kişi Başına GSYH & 40559.26 & 14228.25 & 20118.09 & 94764.98 & 196 \\
\hline Ticari Açıklık & 105.5956 & 67.4874 & 26.57992 & 410.1716 & 196 \\
\hline Yatırım & 20.89596 & 2.943138 & 13.9361 & 31.82328 & 196 \\
\hline Enflasyon & 1.436551 & 1.379454 & -1.14392 & 5.66764 & 196 \\
\hline Nüfus & $3.50 \mathrm{E}+07$ & $6.20 \mathrm{E}+07$ & 318041 & $3.23 \mathrm{E}+08$ & 196 \\
\hline Kamu Harcaması & 20.284 & 3.348477 & 11.6021 & 27.36583 & 196 \\
\hline
\end{tabular}

\section{Gelişmekte Olan Ülkelerin Açıklayıcı İstatistikleri}

\begin{tabular}{|l|l|l|l|l|l|}
\hline Değişken & Ortalama & Std. Sapma & Minimum & Maksimum & Gözlem Sayısı \\
\hline Kişi Başına GSYH & 12148.53 & 5714.305 & 2929.829 & 25668.88 & 208 \\
\hline Ticari Açıklık & 69.52302 & 34.42648 & 21.12435 & 165.6459 & 207 \\
\hline Yatırım & 23.16439 & 6.872992 & 12.4456 & 50.4062 & 207 \\
\hline Enflasyon & 8.036278 & 20.25435 & -0.90016 & 254.9485 & 206 \\
\hline Nüfus & $5.57 \mathrm{E}+07$ & $6.54 \mathrm{E}+07$ & 2817210 & $2.61 \mathrm{E}+08$ & 210 \\
\hline Kamu Harcaması & 14.01785 & 3.584603 & 5.935159 & 21.63427 & 207 \\
\hline
\end{tabular}

\section{REFERENCES / KAYNAKLAR}

Abrams, B. A. (1999). The effects of government size on the unemployment rate. Public Choice, 99(3-4), 395401.

Alcalá, F. \& Ciccone A. (2004). Trade and productivity. Quarterly Journal of Economics, 119(2), 613-46.

Anwer, M. S. \& Sampath, R. K (1999). Investment and economic growth. Presented at Western Agricultural Economics Association Annual Meeting, July 11-14, 1999, Fargo, ND, (No. 1840-2016-152256).

Arellano, M. (1987). Computing robust standart errors for within group estimators. Oxford Bulletin of Economics and Statistics, 49(4). 431-434.

Bahmani-Oskooee, M. \& Niroomand, F. (1999). Openness and growth: An empirical investigation. Applied Economics Letters, 6, 557-561.

Barro, R. J. (1995). Inflation and economic growth. NBER working paper no. 5326, National Bureau of Economic Research.

Bejan, M. (2006). Trade openness and output volatility. Available at SSRN 965824.

Bonga-Bonga, L. \& Kinfack, E. (2019). The growth effect of trade openness on African countries: Evidence from using an Instrumental Variable Panel Smooth Transition Model. Munich Personal RePEc Archive. Erişim tarihi 20.08.2019, https://mpra.ub.uni-muenchen.de/id/eprint/92111

Brunner, A.D. (2003). The Long-Run Effects of Trade on Income and Income Growth. IMF Working Paper WP/03/37. Washington, DC: IMF Institute.

Busse M. \& Königer J. (2012). Trade and economic growth: A re-examination of the empirical evidence. Hamburg Institute of International Economics HWWI Research Paper, 123, 1-25. 


\section{Kovacı, $S$.}

Chang, R., Kaltani, L. \& Loayza, N. V. (2009). Openness can be good for growth: The role of policy complementarities. Journal of Development Economics, 90(1), 33-49.

Dowrick, S. \& Golley, J. (2004). Trade openness and growth: Who benefits? Oxford Review of Economic Policy, 20, 38-56.

Driscoll, J. C. \& Kraay, A. C. (1998). Consistent covariance matrix estimation with spatially dependent panel data. Review of Economics and Statistics, 80, 549-560.

Dufrenot, G., Mignon, V. \& Tsangarides, C. (2010). The trade-growth nexus in the developing countries: A quantile regression approach. Review of World Economics, 146(4), 731-761.

Easterlin, R. A. (1967). Effects of population growth on the economic development of developing countries. The Annuals of the American Academy of Political and Social Science, 369(1), 98-108.

Fetahi-Vehapi M., Sadiku, L. \& Petkovski, M. (2015). Empirical analysis of the effects of trade openness on economic growth: An evidence for south east European countries. Procedia Economics and Finance, 19, 17-26.

Fischer, S. (1993). The Role of Macroeconomic Factors in Growth. Journal of Monetary Economics, 32(3), 485512.

Frankel J. A. \& Romer D. (1999), Does trade cause growth? American Economic Association, 89(3), 379-399.

Freund, C. \& Bolaky, B. (2008). Trade, regulations, and income. Journal of Development Economics, 87(2), 309321.

Froot, K. A. (1989). Consistent covariance matrix estimation with cross sectional dependence and heteroskedasticity in financial data. Journal of Financial and Quantitative Analysis, 24(3). 333-355.

Greene, W. (2000). Econometric analysis, upper saddle river. NJ: Prentice--Hall.

Hausman, J. A. (1978). Specification tests in econometrics, Econometrica, 46, 1251-1271.

Herzer, D. (2013). Cross-country heterogeneity and the trade-income relationship. World Development, 44, 194211.

Huchet, M., Le Mouël, C. L. M. \& Vijil, M. (2011, August). The relationship between trade openness and economic growth: some new insights on the openness measurement issue. Erişim tarihi: 17.09.2019, https://halagrocampus-ouest.archives-ouvertes.fr/hal-00729399/file/A2_-_78_VIJIL.pdf

Kali, R., Mendez, F. \& Reyes, J. (2007). Trade structure and economic growth. The Journal of International Trade \& Economic Development, 16, 245-269.

Kim, D. H. \& Lin, S. C. (2009). Trade and growth at different stages of economic development. Journal of Development Studies, 45(8), 1211-1224.

Kim, D. H., Lin, S. C. \& Suen, Y. B. (2011). Nonlinearity between trade openness and economic development. Review of Development Economics, 15(2), 279-292.

Lee, H. Y., Ricci, L. A. \& Rigobon, R. (2004). Once again, is openness good for growth? Journal of Development Economics, 75(2), 451-472.

Li, K., Morck, R., Yang, F. \& Yeung, B. (2004). Firm-specific variation and openness in emerging markets. Review of Economics and Statistics, 86(3), 658-669.

Loizides, J. \& Vamvoukas, G. (2005). Government expenditure and economic growth: Evidence from trivariate causality testing. Journal of Applied Economics, 8(1), 125-152.

Irwin, D. A. \& Terviö, M. (2002). Does trade raise income?: Evidence from the twentieth century. Journal of International Economics, 58(1), 1-18. 
Noguer, M. \& Siscart M. (2005). Trade raises income: A precise and robust result. Journal of International Economics, 65, 447-460.

Pesaran, M. H. (2004). General diagnostic tests for cross section dependence in panels. Cambridge Working Papers in Economics, No. 0435. Erişim tarihi: 25.01.2018, http://www.econ.cam.ac.uk/researchfiles/repec/cam/pdf/cwpe0435.pdf

Rassekh, F. (2007). Is international trade more beneficial to lower income economies? An empirical inquiry. Review of Development Economics, 11(1), 159-169.

Rogers, W.H. (1993). Regression standard errors in clustered samples. Stata Technical Bulletin, 13, 19-23.

Salinas, G. \& Aksoy, A. (2006). Growth before and after trade liberalisation. World Bank.

Sakyi, D., Villaverde, J., Maza, A. \& Reddy Chittedi, K. (2012). Trade openness, growth and development: Evidence from heterogeneous panel cointegration analysis for middle-income countries. Cuadernos de Economía, 31(SPE57), 21-40.

Sakyi D., Villaverde J. \& Maza A. (2015), Trade openness, income levels, and economic growth: The case of developing countries, 1970-2009. The Journal of International Trade \& Economic Development, 24(6), 860-882. Doi: 10.1080/09638199.2014.971422.

Squalli, J. \& Wilson, K. (2011). A new measure of trade openness. The World Economy, 34(10), 1745-1770.

Tatoğlu, F. Y. (2012). Panel veri ekonometrisi. İstanbul: Beta Yayıncılık.

Tekin, R. B. (2012). Development aid, openness to trade and economic growth in least developed countries: Bootstrap panel Granger causality analysis. Procedia-Social and Behavioral Sciences, 62, 716-721.

Ulaşan, B. (2015). Trade openness and economic growth: Panel evidence. Appl. Econ. Lett, 22(2), 163-167.

United Nations. (2014). World Economic Situations and Prospects.

Vamvakidis, A. (2002). How robust is the growth-openness connection? Historical evidence. Journal of Economic Growth, 7(1), 57-80.

Villaverde, J. \& Maza, A. (2011). Globalisation, growth and convergence. The World Economy, 34(6), 952-971.

Vlastou, I. (2010). Forcing Africa to open up to trade: is it worth it? The Journal of Developing Areas, 44(1), 2539.

Were, M. (2015). Differential effects of trade on economic growth and investment: A cross-country empirical investigation. Journal of African Trade, 2(1-2), 71-85.

Winters, L. A. (2004). Trade liberalisation and economic performance: an overview. The Economic Journal, 114(493), F4-F21.

Wooldridge, J. M. (2002). Econometric analysis of cross section and panel data. Cambridge, MA: MIT Press.

World Bank. (2018). World Development Indicators. Washington, D.C. Erişim tarihi: 20.08.2019, https://data.worldbank.org/indicator/NE.TRD.GNFS.ZS

Yanikkaya, H. (2003). Trade openness and economic growth: a cross-country empirical investigation. Journal of Development Economics, 72, 57-89.

Zahonogo P. (2016). Trade and economic growth in developing countries: Evidence from sub-Saharan Africa. Journal of African Trade, 3, 41-56. 